\title{
Research on Training of Intercultural Communicative Competence for College Students
}

\author{
Haiyan Sun \\ College of Foreign Languages, Bohai University, Jinzhou, 121013, China \\ sunhaiyan0@163.com
}

\begin{abstract}
Keywords: college students; intercultural communicative competence; composition theory; training mode; training strategy
\end{abstract}

\begin{abstract}
With the integration of the world economy, the international era has come, and the demand for the talents with intercultural communication is becoming more and more urgent, and the research on the cultivation of College Students' intercultural communicative competence has important theoretical and practical significance. Through the in-depth analysis of the theory of intercultural communication competence and intercultural communicative competence training model, and combined with previous research results, this study proposes the following strategies of College Students' intercultural communication competence: The use of multimedia and Internet to expand cross-cultural communication experience, change the mode of thinking of college students, through the non verbal communication awareness to enhance students' intercultural communication sensitivity, strengthen the guidance of students' cross-cultural awareness, and promote their own cross-cultural literacy.
\end{abstract}

\section{Introduction}

With China's foreign exchanges and cooperation in various fields such as politics, economy, culture and so on, the international exchange of science and technology, finance, environmental protection, industry and other fields is increasing. It needs a large number of talents with international quality. The need to have the ability of cross culture communication is becoming urgent. In order to meet the communication and communication in the context of globalization, higher education and training of talents not only need to have a solid professional knowledge, but also must have a high cross-cultural communication ability, so as to meet the needs of social and national progress and development. College students in their studies, employment, friends, leisure and other aspects will be faced with a variety of cross-cultural communication, effective cross-cultural communication skills is the essential quality of college students in multicultural society [1]. The cultivation of College Students' intercultural communication ability is a complicated system engineering. Higher education should be in the open social environment to engage in personnel training, to study the new situation of the new problems, open up new areas of education.

\section{Composition Theory on Intercultural Communicative Competence}

Spitzberg considers that the intercultural communication competence is composed of three factors: knowledge, motivation, and skill. The three influence each other [2]; Wineman will be able to communicate more effectively as a kind of knowledge, emotion and skill which can make the communication between individuals and organizations of different cultural backgrounds; Kim use social psychology, applied linguistics and sociology method, the influence of the factors of intercultural communication ability, forming a new cross-cultural communicative competence model. He believes that intercultural communication ability is composed of cognitive ability, emotional ability and behavior ability, and the three are interrelated and interact with each other. In this paper, based on the view of Kim, the relationship between the elements and the relationship between the factors and the relationship between the cultural and communicative competence is shown in Fig. 1 [3].

(1) Cognitive ability elements. Cognitive ability refers to the ability of the human brain to 
process, store and extract information, that is, the structure and performance of the people, the relationship between the performance and the material, the development of the power, the direction of development and the basic law of the ability to grasp. Cognitive ability is the most important psychological condition for the successful completion of the activity.(1) perception, memory, attention, thinking and imagination are all considered to be cognitive. Cognitive ability elements include three aspects, one is the cultural communication system, namely, the cultural knowledge and pragmatic knowledge; two is the cultural understanding, namely understanding of the history, politics, religion, value and other aspects of knowledge; three is the ability to integrate information, that is, the ability to integrate information.

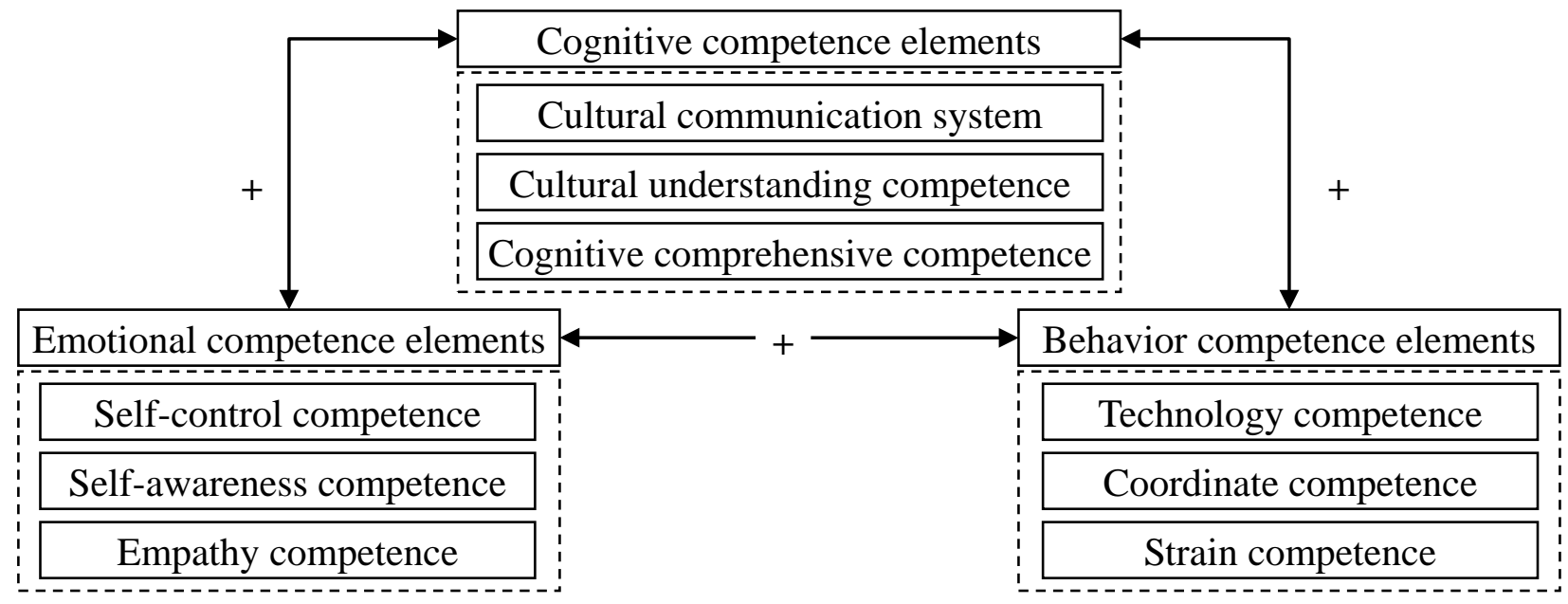

Fig. 1. Constituent elements on intercultural communicative competence

(2) Emotional competence elements. Emotional competence is a comprehensive ability to gain insight into the relationship between themselves and others, self motivation, self management and interpersonal skills. Emotional intelligence is a kind of comprehensive ability which is based on the emotional quotient. It is embodied in the aspects of self adjustment, self - awareness, empathy, and so on. Self regulation ability refers to the control of emotional and emotional pain, keep the mind awake, cheer, calm, self perception is the ability to regulate themselves, grasp the control mood, to maintain the initiative, and to maintain the ability to coordinate with the surrounding environment, the ability to perceive other people's emotions, to determine the ability of others to think of a series of subtle changes.

(3) Behavior ability elements. Capacity is the ability to exercise their rights and obligations in accordance with the law. Communication is a kind of behavior, communicative competence is reflected in the specific communicative behavior, the behavior of intercultural communication is the ultimate embodiment of cross-cultural communicative competence. The ultimate form of behavior ability needs the knowledge to support, and the emotional competence is the foundation to express the individual's cognition and emotion. Cross cultural behavior ability includes three aspects, one is the ability to obtain useful information, to solve the problem of different skills, coordination ability, communication ability and the local people in harmony with the ability to get along with the local people, the ability to use appropriate communication strategies to solve the problem, the ability to achieve the goal of communication.

\section{Training Mode on Intercultural Communicative Competence}

Cross culture communication ability training mode is based on the needs of cross culture communication, and to guide the training of theory, training objectives, training principles, training content and training process, etc., in the global cultural awareness, cultural debugging ability, communication and cultural knowledge and practice ability, etc.. Cross cultural communication ability training mode is shown in Fig. 2.

The five directions shown in Fig. 2 are as follows [4]: (1) Training idea, the main line of intercultural communicative competence should be penetrated into the college teaching and related 
links, forming a complete cross-cultural communicative competence training system; intercultural communicative competence should be infiltrated into the students' individual development, and students are the main body. (2)Training target, students in the knowledge, ability, attitude, quality of the four part of the comprehensive development and upgrading, and ultimately to achieve the ability of cross-cultural communication and sustainable development and sustainable development. Although the training objectives need to be realized gradually, the content and training process of intercultural communicative competence should be guided by the complete training objectives. (3) Training principle, culture connotation clear, emphasizing the dynamic and developing characteristics of culture, take the student as the main body, and from outside to inside, combination of inside and outside, from quantitative change to qualitative change; training system, pay attention to the interaction between subjects, the joint action of the ring, to form a complete cross cultural communicative competence training system; training mode diversification, using a variety of ways to penetration of nourishing, combination of knowledge, ability, communicative practice; training process gradually evolved and need to gradually infiltration, cultivate and improve, is a progressive and gradual penetration process. (4) Training content, to realize the balanced development of students in knowledge, ability, attitude, quality and so on, and focus on the common cultivation of the dominant and recessive factors in intercultural communication. Knowledge part of the training includes cultural knowledge, language knowledge, social knowledge and professional knowledge, ability of some training, including communication ability, social ability, learning ability and professional ability, attitude part of training should pay attention to students' communicative attitude and open mind, pay attention to students learning interest, cross-cultural communication, intercultural communication awareness, international perspective. (5)Training link, the realization of the goal of intercultural communicative competence training depends on the teaching of all aspects of the teaching, involving the course standard / teaching requirements / syllabus / course / teaching / teaching / teaching / testing and evaluation.

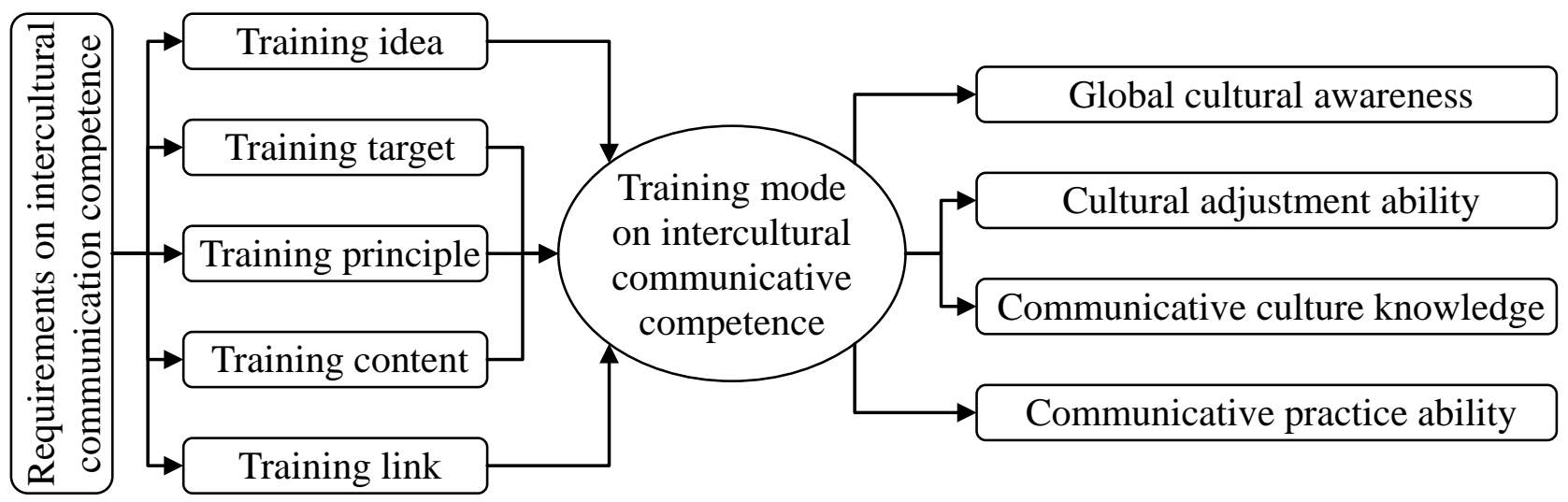

Fig. 2. Training mode on intercultural communicative competence

The following: (1) Global cultural awareness. In the of the nation and national social and cultural knowledge on the basis of accumulation, rejects ethnocentrism, eliminate cultural bias of relativism attitude that culture from basically no good and bad points, but there are differences. Understand the differences of people's communication behaviors in different cultures, and to seek the cultural origin of the differences. (2) Cultural adjustment ability. An ability to adjust its behavior according to the cultural characteristics, including the ability of psychological adjustment and the ability to adapt to the flexibility. Psychological adjustment ability mainly refers to the psychological state in the timely adjustment of the cultural conflict, try to reduce the uncertainty, as far as possible to reduce the pressure, to maximize the ability to relax. Flexible strain capacity is the use of communication culture, cross-cultural thinking and communication strategies, to deal with all kinds of communicative context of cross-cultural context. (3) Communicative culture knowledge. Embodied in the teaching of values, life, customs, history and religion. On the one hand, through the introduction of cultural knowledge points to achieve; on the other hand, rely on the continuous improvement and enhance the communicative competence. (4) Communicative practice ability. 
Language communicative competence, nonverbal communicative competence and communicative strategies are emphasized, and the comprehensive use of various knowledge such as language, non language, communication culture, etc.. Language communicative competence includes linguistic competence, pragmatic competence and discourse competence, nonverbal communicative competence is the ability to understand and use nonverbal behaviors, as well as the communicative competence and communicative competence.

\section{Training Strategy on Intercultural Communicative Competence}

Through in-depth analysis of the theory of intercultural communication competence and intercultural communicative competence training model and combined with previous research results, this paper puts forward the strategies of intercultural communication competence of college students as follows [5-8]:

(1) Cross cultural communication experience with the use of multimedia and internet. The use of multimedia to broaden the students' knowledge is helpful to students' understanding of the specific rules of language. The language and non language communication means, communication rules and communication patterns of the film and television are helpful to improve the students' sensitivity to the differences. the development of network technology provides more learning resources for the contemporary college students, through the use of cross culture communication on the Internet and the ability to develop cross-cultural communication and other resources, make full use of the Internet to expand cross-cultural communication experience.

(2) Change the mode of thinking of College students. Thinking way is to look at things from the perspective of ways and methods, the people's words and deeds play a decisive role. From the perspective of communication culture, the content of college teaching should lead students to pay attention to the cross-cultural communication and interpersonal relationship. Because of the different ways of thinking in different nations, in the process of communication, there are often some confusion, which affects the communication effect. Therefore, teachers should teach students the communication etiquette from the angle of the guide, and inspire the students to put forward the differences in communication, encourage the students to give more examples of communication differences, let the students understand the cultural background knowledge, train the students to understand and accept the way of thinking in the West.

(3) Improving students' intercultural communication sensitivity by non verbal communication. Intercultural sensitivity is one of the components of intercultural communication. It is the subjective intention of people to stimulate their own understanding, appreciation and acceptance of cultural differences. Through the non verbal communication, the students can learn nonverbal information. Through life experience, the students can find out the differences of nonverbal behavior in different cultural backgrounds. Through the non verbal communication, the students have to know the non speech information symbols; through the life experience, the students are guided to find out the differences of nonverbal behaviors in different cultures. To guide students from the details, pay attention to the non verbal communication, and gradually improve the sensitivity of intercultural communication.

(4) To strengthen the guidance of the teacher to the students' cross-cultural awareness. Teachers should constantly excavate the cultural information in the teaching, in the "teaching" and "learning" of the interactive relationship, to guide students to understand and grasp the western culture. The culture of cross cultural communication competence should be combined with the daily communication. Teachers should not only teach the knowledge of common knowledge, but also create a variety of language situations, which embody the cultural differences. This paper introduces the communication rules and linguistic norms of cultural differences between Chinese and Western culture, and the introduction of western culture and language learning, so that students can realize the experience and comprehension of cultural knowledge in real language situations.

(5) To improve the cross cultural qualities of the teachers themselves. Teachers are the teachers of language, but also the communicators of culture. In the process of cultivating students' intercultural communicative competence, the leading role of teachers should not be ignored. 
Universities should establish the training mechanism to enhance the cultural quality of teachers, to take "going out" and "bringing in". The teacher needs to take the initiative of Reinforcement learning foreign culture, a lot of knowledge about cross-cultural background, in the learning and mastery of western culture, but also pay attention to the comparison and difference between local culture and Western culture.

\section{Conclusion}

Cross cultural communication is developed on the basis of a cross discipline in Bocaizhongzhang to attract the theoretical achievements of many disciplines, in ordinary communication science communication theory, devoted to the study of cross cultural communication in the contradictions and problems, to explore how to improve intercultural communicative competence. Therefore, intercultural communicative competence should be improved in order to enhance the cultural communicative competence and to improve the ability of cultural communication. Any thinking and practice to improve the ability of cultural communication can be incorporated into the category of intercultural communication teaching. Twenty-first Century is the time for China to open up the pace of opening up to the outside world, and to integrate with the international community. It is a time for the contemporary college students to be able to talk with each other from different countries, different races and different nations, Chinese society is facing the tension of multi culture, intercultural communication as a phenomenon of the contemporary society is becoming increasingly prominent, The era of cross cultural communication has come, and the study of College Students' intercultural communicative competence has important theoretical and practical significance.

\section{References}

[1] R. P. Zhu, "Cultivation of contemporary college students' intercultural communicative competenceTaking 'cross cultural communication' teaching as an example," News Dissemination, vol. 28, no. 1, pp. 9-11, 2012.

[2] L. Gao, F. Wang, "A tentative approach to intercultural communicative competence," Journal of Northwest University (Philosophy and Social Sciences Edition), vol. 37, no. 3, pp. 116-119, 2007.

[3] J. Y. Wang, "The main factors affecting intercultural communication competence," Heihe Journal, vol. 30, no. 5, pp. 100-101, 2010.

[4] W. D. Dai, "On Constructing a Comprehensive Model of Intercultural Communication Competence Development," Doctor's degree of Shanghai International Studies University, 2014.

[5] M. Zhao, L. D. Zhang "Practice and strategy of Cultivating College Students' intercultural communicative competence in College English Teaching," Journal of Hubei University of Economics(Humanities and Social Sciences), vol. 7, no. 6, pp. 189-190, 2010.

[6] Y. F. Lin, "Strategies for Improving Students' Intercultural Communicative Competence in Ubiquitous Learning," Journal of Ningbo University(Educational Science Edition), vol. 35, no. 1, pp. 106-110, 2013.

[7] R. F. Shi, J. Zhang, "On the cultivation of intercultural communicative competence in College English Quality Education," Journal of Liaoning Institute of Technology (SOCIAL science Edition), vol. 17, no. 3, pp. 1-3, 2015.

[8] L. Wu, "Strategy of College Students' intercultural communication competence," Educational exploration, vol. 34, no. 6, pp. 91-92, 2014. 